\title{
Assessment of the quality of the housing environment, taking into account selected climate conditions
}

\author{
Justyna Kobylarczyk ${ }^{1, *}$ \\ ${ }^{1}$ Justyna Kobylarczyk, Cracow University of Technology, Faculty of Architecture, Institute of Urban \\ Design, Chair of Housing
}

\begin{abstract}
For centuries, we have been observing the influence of nature on the conditions of human life, whose relationship with the natural environment has weakened during the period of changes brought about by the industrial revolution. However, the growing awareness of society about the dwindling resources of nature and the necessity to protect them resulted in the rediscovery of the importance of activities expressing concern for the state of the environment. It is consistent with the idea of sustainable development striving for rational management of natural resources. We also increasingly notice the possibility of using climatic factors to create optimal living conditions, taking into account, among other things, the relevant parameters of the objects. The article presents an analysis of climatic factors affecting the quality of the housing environment. These factors can be used in the pursuit of minimising energy consumption throughout the life cycle of buildings and for construction that utilises advanced technologies. Respecting the climate conditions in planning buildings of an appropriate scale, form and location is of great importance for shaping comfortable housing environments. It is planning that allows the symbiosis of architecture and the environment, which becomes a challenge of modern times.
\end{abstract}

\section{Introduction}

The image of the cities and the way they function is undergoing constant transformations. The reasons for these transformations include changes in the form of life, growing public awareness of their rights and the possibility of co-managing the housing environment. Noticeable changes in the lifestyle also stem from the new structure of families, and different preferences concerning the residential areas connected with the ageing of the population. The city and its residential areas are assessed and perceived differently due to the higher technological possibilities that favour flexible solutions, raise the standard of architecture, but also pose a threat to urban solutions, replacing the real space with the virtual one. Therefore the housing environment provides comfortable conditions in a different way. One of the trends in shaping the housing environment includes sustainable design expressing

* Corresponding author: j.kobylarczyk@op.pl 
concern for modern man and future generations, as well as for the condition of the natural environment mostly dependent on the climatic factors. Due to anthropogenic activities, both the environment and the climate were transformed. The development of industry and the increase of the built-up area at the expense of green, open spaces can be considered as the main reasons. The green roofs or walls are more and more often perceived as biologically active areas, yet they do not provide the same opportunities as recreational spaces. Too much intensity of the buildings also limits the size of the neighbourhood zones, which not only allow for closer contacts between the residents of housing estates but also favour the lighting of residential and urban interiors and enable proper ventilation. It should be noted that the public's awareness of the need for a holistic view of the environment is growing. Until recently, inhabitants willingly resigned from the possibility of co-managing the housing environment (as evidenced by the author's research) [1]. The ongoing degradation of the environment necessitates the comprehensive and coordinated action in the field of spatial planning for the protection of the natural environment. It must also include rational planning and management of the areas with regard to their cultural values [2]. Climate change caused by strong urbanisation and responsible for the degradation of the natural environment has become one of the negative signs of modernity. Today, green areas are replaced by artificially shaped ground, spaces and passageways, creating specific climatic conditions within the city. Reduction of the size of green areas contributes to the increase of air pollution. Radiation interaction leading, among other things, to changing the components of the radiation balance is also an unfavourable phenomenon. (Fortuniak 2003) [3]. The changing climate has an impact on human health. It mostly concerns cities, which are the primary place of residence of a modern man. The intensively built-up area accompanying the towns, excess heat and the weakening of the air exchange, which further slowed the speed of the wind, hindered the air circulation. In addition, the buildings have become the main cause of the change in the direction of the wind [4]. Climate change is a natural phenomenon, but it's global warming that has been breaking records in recent decades. In a one hundred and fiftyyear period, there has never before been such a high temperature rise, additionally accompanied by strong fluctuations. In 1996, 1999, 2000 and 2008, the global temperature was lower than indicated by its long-term upward trend, while in 1998 and 2005 the temperature was higher. It can therefore be assumed that global warming does not have a steady pace [5].

„In Poland, the average long-term value of insolation is the highest for Kotobrzeg and amounts to 1624 h/year, for Warsaw it is $1579 \mathrm{~h} /$ year, and for Zakopane $1467 \mathrm{~h} /$ year" [6].

Insolation in Poland is presented on figure 1 [7].Insolation on the horizontal surface for Krakow figure 2 [8]. 


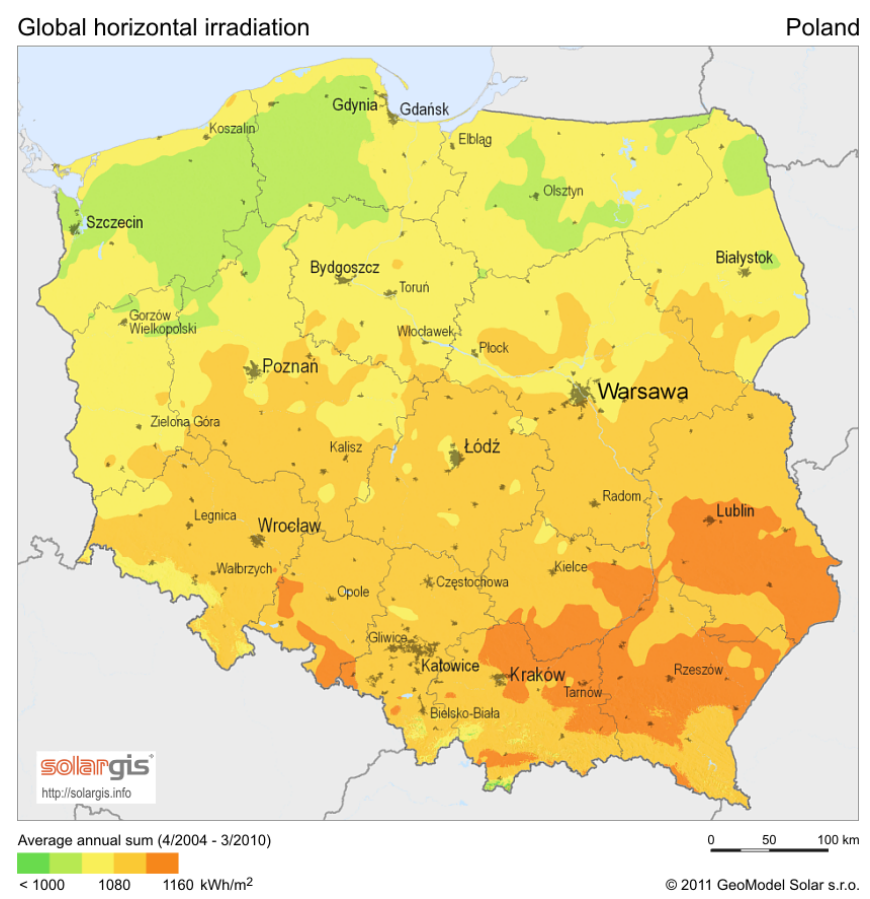

Figure 1. Insolation in Poland.

Source: (http://solaris18.blogspot.com/2011/09/nasonecznienie-usonecznienie-i.html).

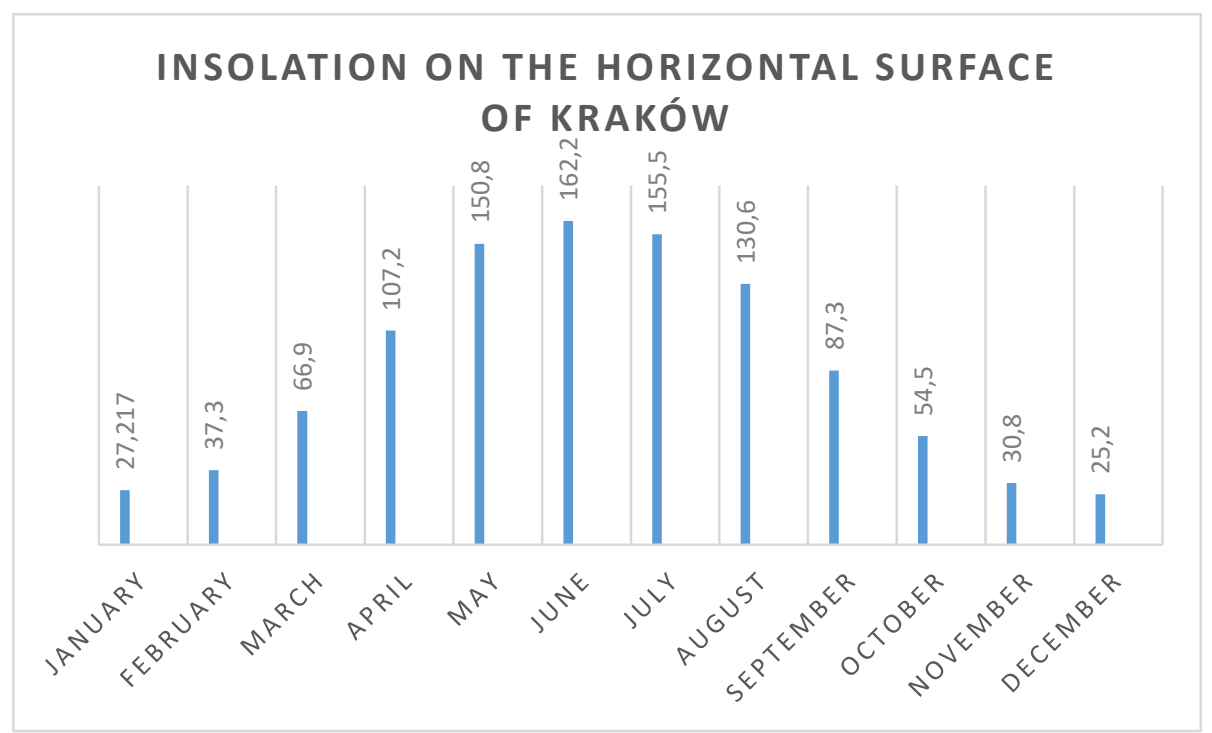

Figure 2. Insolation on the horizontal surface for Krakow.

Based on: http://solaris 18.blogspot.com/2011/05/jak-dobrac-liczbe-kolektorow.html. 


\section{The importance of climatic conditions in the assessment of the housing environment}

The assessment of the living environment of a man is affected by a wide range of problems, which due to its complexity often leads to the loss of objectivity. The analysis of the problem requires proper selection of elements, phenomena and factors subjected to evaluation. Each area has its specificity shaped by individual characteristics. Therefore it is difficult to determine which meters are universal enough that they can be referenced to any location regardless of the region, city or district.

The author's research proved what elements and factors of the residential environment of small towns of Podkarpacie might have a particular significance for their inhabitants. The most appreciated include safety, access to green spaces and basic services, especially proximity to health centres and pharmacies, as well as an attractive view from the window, and a sense of intimacy and peace [9]. To create such conditions, it is necessary to take into account many parameters indicating favourable distances and a friendly scale of the environment.

The process of creating urban interiors should take into consideration many indicators, climatic factors and, above all, the needs of present and future users. The BIM system is a useful tool supporting the coordination and management of the project work as well as the operation of the facility. It also ensures control over the entire implementation of the project, starting from the first concept idea, through the investment project and cost estimation. The assessment of the conditions based on the urban analysis is frequently supported by sociological research. The multi-layered nature of the study, as well as its subject matter, requires the use of interdisciplinary research methods combining knowledge of many scientific disciplines.

The assessment of the housing environment can be made on different scales. Starting from a macro-scale that takes into account the conditions in the city, it then moves through the mesoscale, including the assessment of conditions characteristic for the district and housing estate and ending with the micro-scale referring to the neighbourhood within the housing complex. The analysis of functional and spatial requirements is complemented by the study of climatic factors and their impact on the quality of the housing environment.

The diagnosis of spatial - compositional - physiognomic conditions as well as the urban analysis is the basis for further considerations about the comfort of living. Regardless of the applied research method, it seems to be essential to refer to contemporary trends in creating the housing environment based on the concept of sustainable development, including sustainable design. One of the assumptions characteristic for this concept is the preservation of the relationship between the natural and built environment, shaped by the city structure. Climatic factors which are subjected to change at various levels and on different scales are important elements of this relationship.

It should be noted that the impact of climatic factors in cities differs from how they affect suburban areas. It is reflected primarily in the distribution of air temperature, its circulation and humidity, as well as insolation.

Research conducted by D. Matuszko and K. Piotrowicz, in Krakow and Balice, confirmed the differences in air humidity in the indicated locations. Urban areas are characterised by lower relative humidity values, which means that it is possible to distinguish a larger number of dry days and fewer days with fog. Climate change in urban areas is primarily the result of increased building intensity, reduction of biologically active replaced by concrete and asphalt surfaces [10].

The climate of the city in the border area is the result of the impact of natural climatic factors and factors shaping the built environment. These impacts include the development, industry and communication zones. The spatial and climatic conditions within a specific 
neighbourhood and thus the area directly adjacent to the buildings of the analysed housing complex are of particular importance for the development of housing areas or the improvement of their quality. In this case, microclimatic conditions with a range of 1000 meters [11].

Environmental trends in shaping housing areas, also include shaping urban spatial development and lead to seeking for solutions that improve the quality of heavily urbanised spaces, using knowledge on the relationship between the spatial development of buildings and the impact of the climatic factors. These phenomena allow for a rational transformation of the living environment and the introduction of new structures aimed at minimalising the climatic problems of the cities. It is important to minimise the areas dominated by detached houses and strive to maintain a balance between buildings and free areas, which in the residential zones acquire a form of corridors allowing the exchange of the air [12].

As noted by K. Zielonko-Jung and J. Marchwiński, the layout of the corridors is optimal when it follows the natural breeze movement from the cooler surrounding areas, water reservoirs or hills. The passages should be tightly built only in the areas of strongly cooling winds. In other situations, the arrangement of the building that allows for side exchange between the corridor and neighbouring building areas is favourable [13].

The ventilation hygiene is just one of the phenomena resulting from the impact of climatic factors on the housing area and at the same time affecting the comfort of the residence. Ventilation and lighting of the interiors are favoured by quarter buildings and slightly less favourable band-like forming of the objects, which allows minimising the shadowing of objects, as well as rational, functional separation of the interior and the building. The principle of the location of objects known already from the times of Descartes takes into account the properties of the respective sides of the world and creates the possibility of obtaining optimal conditions not only because of the interior lighting but also due to the proper air circulation. In the case of excessive building intensity, it is limited. Hence it is recommended to introduce breaks in the building development and use greenery, which is also a water-permeable substrate that regulates the humidity and temperature of the air. It may cause shading and constitute a barrier against too strong gusts of wind [14].

The least favourable microclimatic conditions occur when the distance between the objects is too small, and they are too high. Then the interiors of the objects are overheated, or poorly insolated. Thus they are chilled and permanently shaded, which in the absence of ventilation leads to stuffiness and high humidity. The distance (depending on the orientation of the objects in relation to the sides of the world) expressed by 1.5 to 3 times the building height is considered to be the right ratio of the building's height to its distance in relation to the nearby object. Difficult conditions arise when the distance between the buildings is less than $1.4 \div 1.5$ to the height of the building. Unfortunately, these values are not respected, especially in central city zones, which is why small buildings are frequently overheated and poorly ventilated in the summer. At night, the temperature is often optimal, which minimises the need for air-conditioning. The most significant drawback is poor interior lighting, especially on the ground floor level [15].

\section{Conclusions}

Issues related to the housing environment are complex and require the analysis and evaluation based on interdisciplinary research methods. The satisfaction of the residents connected with the inhabited area seems to be the most important. Hence the functional and spatial analyses are combined with environmental research, which allows obtaining information about the opinions of the inhabitants about their place of residence, their expectations and preferences. One of the most urgent modern human needs is the pursuit of 
a healthy lifestyle, which is supported by the right microclimate and high quality of functional and spatial solutions.

The information provided make it possible to claim that there is a close relationship between the built environment and the microclimate. These relations are reciprocal: buildings affect the climate, and the climate changes the conditions prevailing in residential areas. These relations are influenced, among other things, by the geometry of the building, its band-shaped or block development, which seems to be the most convenient type in the typology of residential buildings eliminating the interior shading. The method of shaping buildings can also affect the minimisation of adverse climatic phenomena by, for example, differentiation of the height of the objects. This intervention promotes air circulation or creates breaks with appropriate location and size in the construction continuity.

The assessment of the quality of the residential environment should also include the areas of greenery - their size and method of development. Greenery regulates the humidity of the air. It also affects the temperature by shading the interior and cooling it down. Moreover, it acts as a windshield modelling band-shaped greenery systems.

\section{References}

1. Kobylarczyk J., (Evaluation of the quality of the housing environment in selected cities of the Podkarpackie Province, after the transformation period, in the first decade of the 21st century, Cracow University of Technology, Kraków 2013)

2. Ziobrowski Z., Kudłacz T., Ney B., Bielecka E., Słysz K., Wańkowicz W., Adamski J., Węglowski M., Kowalewski A., Jeżak J., Korecki D., (Spatial management in Poland in the light of cohesion with the European Union - conditions, directions of changes, Research Project No. 2h02c02025, Institute of Urban Development in 2003-2005, Kraków)

3. Fortuniak K., (Urban heat island. Energy basics, experimental studies, numerical and statistical models, University of Lodz Publishing House, Łódź 2003)

4. Lewińska J., (The climate of the city. Resources, threats, shaping, IGiK, Kraków 2000

5. Z. Kundzewicz, Climate change and its effects, in Lectures inaugurating the academic year 2010/2011, IPWC, 65.,Warszawa 2011)

6. (http://solaris18.blogspot.com/2011/09/nasonecznienie-usonecznienie-i.html), access : 5.06.2018)

7. (http://solaris18.blogspot.com/2011/09/nasonecznienie-usonecznienie-i.html)

8. http://solaris18.blogspot.com/2011/05/jak-dobrac-liczbe-kolektorow.html access : 5.06.2018)

9. J. Kobylarczyk, (Evaluation of the quality of the housing environment in selected cities of the Podkarpackie Province, after the transformation period, in the first decade of the 21st century, Cracow University of Technology, Kraków 2013)

10. Matuszko D., Piotrowicz K., (Features of the city's climate and the climate of Krakow, www.geo.uj.edu.pl/publikacje.php?pdf=000209_t1_13\&token)

11. Zielonko-Jung K., Marchwiński J., (Environmental aspects of shaping buildings in urban spaces, [in:] Innovative challenges of building technology, Building Research Institute, 131, Warszwa 2017, citation by :Carlo Ratti, The City of Tomorrow: Sensors, Networks, Hackers, and the Future of Urban LifeThe Future Series, Yale University Press, 2016)

12. Zielonko-Jung, K., Marchwiński J., (Environmental aspects of shaping buildings in urban spaces, [in:] Innovative challenges of building technology, Building Research Institute, 133, Warszwa 2017) 
13. Zielonko-Jung, K. J. Marchwiński J., (Environmental aspects of shaping buildings in urban spaces, [in:]Innovative challenges of building technology, Building Research Institute 135, Warszwa 2017)

14. Zielonko-Jung K., Marchwiński J., (Environmental aspects of shaping buildings in urban spaces, [in:] Innovative challenges of building technology, Building Research Institute, 134-137, Warszwa 2017)

15. K. Zielonko-Jung, J. Marchwiński, (Environmental aspects of shaping buildings in urban spaces, [in:] Innovative challenges of building technology, Building Research Institute, 136, Warszwa 2017) 